\title{
GLOBALIZACIÓN, ESPACIO URBANO Y CONSUMO ${ }^{1}$
}

\section{GLOBALIZATION, URBAN SPACE AND CONSUMPTION}

\author{
Iliana Araya Ramírez ${ }^{1}$ \\ ${ }^{1}$ Universidad Nacional de Costa Rica (UNA), Heredia, Costa Rica \\ Correspondência para: Iliana Araya Ramírez (iliana.araya.ramirez@una.cr \\ doi: 10.12957/geouerj.2019.44822 \\ Recebido em: 27 ago. 2019 | Aceito em: 17 set. 2019
}

SCREENED BY

iThenticate

\section{RESUMEN}

El objetivo de este ensayo consiste en explicar la transformación de la ciudad latinoamericana a partir de la transición del modelo de sustitución de importaciones al neoliberalismo. En este contexto estructural, la reestructuración de los espacios urbanos está subordinado a la privatización, el financiamiento de la economía, la administración y la manipulación de las crisis e inversión de la redistribución estatal. En el modelo económico basado en el libre mercado, algunas de las característica son: el cambio de la centralización hacia la descentralización, la segregación e integración espacial resultado del crecimiento desordenado de las ciudades latinoamericanas, el decrecimiento en el tamaño relativo de las ciudades principales, la evolución del mercado laboral y el desempleo, el desmejoramiento en las condiciones de desigualdadad social y el incremento del crimen y victimización. La globalización reorganiza geográficamente los espacios del capital al inducir una profunda fragmentación de los espacios donde coexisten los centros históricos convertidos en espacios de intercambio comercial de bienes y servicios y los espacios construidos por el capital global: los malls, shopping centers, los urban entertainment centers y los business parks. El consumo adquiere centralidad al trascender la necesidad económica y redefinir los patrones culturales urbanos.

Palabras-clave: Globalización, ciudad latinoamericana, consumo, neoliberalismo, mercado inmobiliario.

\begin{abstract}
The objective of this essay is to explain the transformation of the Latin American city from the transition of the import substitution model to neoliberalism. In this structural context, the restructuring of urban spaces is subordinated to privatization, financing of the economy, administration and manipulation of crises and investment of state redistribution. In the economic model based on the free market, some of the characteristics are: the change from centralization to decentralization, segregation and spatial integration resulting from the disorderly growth of Latin American cities, the decrease in the relative size of the main cities, the evolution of the labor market and unemployment, the deterioration in the conditions of social inequality and the increase in crime and victimization. Globalization reorganizes the spaces of capital geographically by inducing a deep fragmentation of spaces where historical centers converted into spaces of commercial exchange of goods and services and the spaces built by global capital coexist: malls, shopping centers, urban entertainment centers and business parks. Consumption acquires centrality by transcending economic need and redefining urban cultural patterns.
\end{abstract}

Keywords: Globalization, Latin American city, consumption, neoliberalism, real estate market.

\section{INTRODUCCIÓN}

\footnotetext{
${ }^{1}$ Este texto forma parte de las reflexiones teóricas realizadas por la autora en la realización de la tesis doctoral. 
La globlalización ha estado presente en la historia del capitalismo desde el descubrimiento de América y se expresa en la reorganización geográfica de los territorios. En la globalización contemporánea algunas de las características fundamentales están centradas en el cambio de escala impulsado por el avance de las Tecnologías de la Información y la Comunicación, donde las distancias se reducen debido al aumento de las velocidades y las telecomunicaciones. En este sentido, el proceso de globalización provoca una ruptura espacio temporal en las formas de movilidad y los flujos tanto de información como de personas. La innovación más profunda ocurre después de 1990 donde las telecomunicaciones revolucionaron las concepciones de distancia y la co-presencialidad se convirte en una alternativa para gestionar la distancia. En las ciudades "[ ] la co-presencia se confirma como el medio mas eficaz para realizar configuraciones interactivas propensas a la innovación" (Lévy, 2012, p. 276). Desde la escala del cuerpo se puede acceder a la escala mundial y convertirla en un universo personal en la co-presencialidad.

El análisis de lo urbano está planteado desde una escala general o dominante a otra local; estas escalas se clasifican como la global, la del estado nacional, la regional y la del lugar. La primera, la escala de la globalización supone una profunda reorganización geográfica del capitalismo (Harvey, 2005) denominada por Milton Santos como la "esquizofrenia del espacio"; la cual produce la disociación del mundo considerado, como abstracto, con su expresión empírica constituida por los lugares. Este autor considera que "El territorio tanto como el lugar son esquizofrénicos, porque de un lado, acogen los vectores de la globalización que en ellos se instalan para imponer su nuevo orden, y, de otro, en ellos se produce una contra orden porque hay una producción acelerada de pobres, excluidos y marginados" (Santos, 2004, p. 93). En esta escala opera el modo de producción dominante; en este nivel, se expresa el tiempo del mundo, donde operan las empresas multinacionales y las instituciones de carácter supranacional. Así, las filiales de tales empresas se ubican en diversos lugares del mundo, de acuerdo a la división internacional del trabajo, e intercambian bienes y servicios al interior de la firma; así [ ] el producto final es el resultado del ensamblaje de partes elaboradas en diferentes países, con lo cual se va perdiendo el concepto made in (Romero y Vera, 2014, p. 61).

Seguidamente, la escala regional opera en el tiempo de las organizaciones supranacionales; por ejemplo, los tratados de libre comercio, además de las culturas regionales (Santos, 2000). En la escala y el tiempo 
del Estado Nación se ubican las grandes firmas nacionales "son los únicos que pueden utilizar plenamente el territorio nacional con sus acciones y vectores" (Santos, 2000, p. 116). A esta escala, lo urbano está legitimado por los intereses de los grupos dominantes; de un lado, las ciudades latinoamericanas se expanden de acuerdo a los intereses neoliberales y de otro, la privatización de bienes y servicios lleva una aboloción de lo público. La evidencia de lo anterior está expresado en la transnacionalización del capital y la eliminación de barreras arancelarias que implanta la hegemonía al interior de los estados. Finalmente, en la escala de lo local resurge el interés por los lugares, aquí operan las empresas medias o pequeñas y los gobiernos locales o provinciales. En el ámbito empírico se encuentra lo local que se opone a lo global y se expresa en los espacios urbanos.

Asociado al cambio de escala, se abre una nueva narrativa histórica la cual debe enfrentar el desafío de la existencia de un nuevo sistema técnico a escala planetaria que transforma el uso del tiempo al producir convergencia y simultaneidad de los momentos en todo el mundo (Santos, 2004). De este modo, la globalización revaloriza la movilidad y los flujos de información y de personas en lo que Harvey (1998) denomina "compresión espacio temporal", en donde se transforma la noción de distancia y se crea la ilusión que todos somos parte de la aldea global.

En suma, la producción del espacio urbano es el resultado de las estrategias de poder ejercidas por los grupos económicos y políticos. La relación entre consumo y vida urbana organiza el eje de producción de la ciudad dadas las diferencias en el poder adquisitivo y acceso al consumo. Es así que América Latina se convierte en la región con mayor desigualdad social en el ámbito mundial, las ciudades secundarias crecen cada día más, en tanto, el mercado laboral está caracterizado por el deterioro en las condiciones de empleo, lo cual incrementa la desigualdad social con claras repercusiones en el crimen y la victimización.

El incremento en la inseguridad latinoamericana limita experimentar la ciudad y enfrentar los miedos [ ] "miedo a la ciudad, miedo al espacio público, miedo a infringir las normas, miedo a apropiarse del espacio, miedo a ultrapasar unas barreras que a menudo son inexistentes, miedo a los demás ciudadanos, percibidos casi siempre como enemigos potenciales" (Careri, 2014, p.4). 
El objetivo de este ensayo consiste en explicar la transformación de la ciudad latinoamericana a partir de la transición del modelo de sustitución de importaciones al neoliberalismo. En el primer apartado se analiza la reestructuración de los espacios urbanos latinoamericanos a partir del cambio en el modelo de sustitución de importaciones hacia la globalización neoliberal caracterizada por la privatización, el financiamiento de la economía, la administración y la manipulación de las crisis e inversión de la redistribución estatal.

En el segundo apartado, se enuncian las características de los espacios urbanos con el cambio en el modelo económico basado en el libre mercado, es decir, el pasaje de la centralización hacia la descentralización, la segregación e integración espacial resultado del crecimiento desordenado de las ciudades latinoamericanas, el decrecimiento en el tamaño relativo de las ciudades principales, la evolución del mercado laboral y el desempleo, el desmejoramiento en las condiciones de desigualdadad social y el incremento del crimen y victimización.

En el tercer acápite se describe la transición de la ciudad polarizada hacia la ciudad fragmentada, según Borsdorf (2003), así como las transformaciones espaciales procudidas en cada etapa del modelo propuesto por el autor. Finalmente, en el cuarto apartado el consumo adquiere centralidad en la ciudad fragmentada al configurar las prácticas socio espaciales en los espacios urbanos. La espacialidad del consumo integra elementos económicos y culturales, ya que el consumo trasciende la necesidad económica al redefinir los patrones culturales urbanos.

\section{La política neoliberal y la reconfiguración de la ciudad latinoamericana}

Las interpretaciones acerca de las transformaciones metropolitanas ocurridas desde mediados de 1970 están, en su mayoría, asociadas a los cambios del sistema económico con la llegada del neoliberalismo y de la globalización. La reconfiguración de la ciudad latinoamericana transforma los procesos culturales, políticos y económicos, lo cuales son reflejados a lo largo de los territorios desde lo local a lo global. El capitalismo configura la expansión y densificación urbana, la función de la ciudad está dirigida a la articular, controlar y gestionar los procesos financieros (Hidalgo, Volker, y Ramírez, 2014). De esta 
forma las estructuras socio espaciales expresan las dinámicas allende sus fronteras; los actores locales interactúan a diferentes escalas, la local, la del Estado, la regional, y la global (Santos, 2004, López, 2008).

El cambio en el modelo de desarrollo sustentado en la sustitución de importaciones hacia el neoliberalismo conduce a reformas económicas que inciden en el debilitamiento del Estado, la privatización de bienes públicos, desregulación en los mercados inmobiliarios, la apertura comercial y el ajuste fiscal, lo cual conlleva la reestructuración espacial de las ciudades (Grimson, 2008; Portes y Roberts, 2008; Janoschka, 2002). El poder del Estado sobre los flujos de capital y dinero ha sido erosionado en las últimas décadas y se ha trasladado al capital financiero y los bonistas. Así, el Estado apoya a las empresas, en detrimento de la ciudadanía; mientras el Estado goza de buena salud, a la población se le ve reducida su capacidad de consumo, especialmente por el deterioro de sus salarios (Harvey, 2014). De acuerdo con Portes (1997) el modelo neoliberal de libre mercado está caracterizado por una apertura unilateral del comercio exterior, privatización de empresas estatales, desregulación de bienes, servicios y el mercado laboral, privatización de los fondos de pensiones al liberalizar los mercados, reestructuración de programas sociales estatales con énfasis en esquemas compensatorios a los grupo con mayores necesitados, agotamiento de la política industrial e incentivos estatales y concentración de la gestión macroeconómica. Tal modelo ha sido direccionado por la homogeneidad del orden internacional dominado por instituciones internacionales como el Fondo Monetario Internacional y el Banco Mundial.

En el libro Ciudades latinoamericanas. Un análisis comparativo en el umbral del nuevo siglo por Portes, Roberts y Grimson (2008) los autores elaboran un análisis de las transformaciones en las ciudades latinoamericanas a partir del cambio de modelo de sustitución de importaciones hacia el modelo neoliberal y plantean la hipótesis que los cambios significativos en el sistema urbano y la vida urbana, a partir de 1980 hasta la primera década de este siglo, está asociada con la trasformación del modelo de desarrollo económico en la región. Para examinar tal hipótesis se realizó un estudio comparativo con seis países que abarcan el 80\% de la población latinoamericana: Buenos Aires, Rio de Janeiro, São Paulo, Santiago, México, Lima y Montevideo. La investigación analiza el cambio del modelo de sustitución de importaciones al modelo neoliberal y la aplicación de las políticas en cuatro áreas: sistemas de primacía 
urbana, desempleo urbano y desempleo informal, pobreza y desigualdad y victimización e inseguridad ciudadana. El éxito las políticas neoliberales está vinculado con la transnacionalización del capital y la eliminación de barreras arancelarias para instaurar su hegemonía al interior de los estados.

No obstante, la evidencia empírica de esta investigación señala que los estados no están en proceso de desaparición, aunque con la aplicación de medidas neoliberales responden de diferentes formas; por ejemplo, en Chile las diferentes políticas han aumentado la desigualdad social; en contraste a Uruguay con menor aplicación de estas, no presenta tanta desigualdad. El neoliberalismo no responde solo a un modelo económico, sino a una configuración sociocultural que resulta de los escenarios de la economía y la política. El impacto de las políticas neoliberales afecta los mercados laborales de las grandes ciudades, a excepción de Chile, mientras en Buenos Aires el desempleo se duplica en el periodo analizado.

Las relaciones de poder que surgen en la ciudad conllevan transformaciones urbanas, donde en forma simultánea se producen homogenización y fragmentación del espacio, su totalización y atomización (Lefebvre y Nicholson-Smith, 1991). Por un lado, disminuyen las diferencias espaciales entre las regiones al interior de los estados, debido al efecto homogeneizador de las tecnologías de la información, las estrategias transnacionales empresariales, las políticas del mercado y las consecuencias del imperialismo cultural (Brenner, 2009). Por otro, se produce una fragmentación del espacio, por ejemplo en las periferias urbanas se establecen áreas residenciales privadas, exclusivas, aledañas a los centros comerciales, y centros educativos privados cercanos a las nuevas áreas residenciales, lo cual incide en el aislamiento de las áreas residenciales de clase baja (Janoschka, 2002). De esta forma, según (Janoschka, 2012) el neoliberalismo y la globalización forman parte fundamental de la reestructuración económica que inciden directamente en la política urbana y territorial, asimismo en los "modos de pensar, percibir, diseñar y gestionar las ciudades..." (p. 89).

En el neoliberalismo la política urbana impone nuevas reglas, regulaciones, y micro-políticas que revalorizan la ciudad y coexisten con la configuración del espacio urbano de otras épocas (Janoschka, 2011). La transformación del espacio urbano es consecuencia de la mercantilización inmobiliaria; la cual configura las ciudades a partir de una diversidad de intereses individuales y grupales, en contextos 
macroeconómicos de desarrollo geográfico desigual gobernados por las reglas de acumulación de capital y poder estatal. De acuerdo con Harvey (2014) la era del neoliberalismo se puede caracterizar a partir de cuatro elementos fundamentales: privatización, financiamiento de la economía, administración y manipulación de las crisis e inversión de la redistribución estatal. La privatización de los activos públicos, la creación de nuevos mercados para bienes comunes como la salud, educación, seguridad, el agua, la propiedad intelectual, elementos culturales, aspectos históricos y arquitectónicos ampliaron las mercancías en las que puede maniobrar libremente el capital.

El financiamiento de la economía responde a un sistema, a un capital ficticio-especulativo de base financiera más poderoso que la economía real, la búsqueda de rentabilidad en el sector vivienda condujo a la especulación inmobiliaria, por medio de las facilidades para acceder a créditos y endeudamiento creciente de la población (Harvey, 2004; Vargas, 2012). La administración y manipulación de las crisis, a favor de las ideas neoliberales, como en el caso de las crisis financieras en Estados Unidos, Unión Europea y América Latina se relacionan con los frágiles sistemas financieros, el débil crecimiento económico y alto desempleo (Vargas, 2012). La funcionalidad económica del Estado respecto a la redistribución ocurre de forma inversa; tal es el caso del aumento a aquellas personas de menor ingreso, destinación de apoyo social a las clases medias, desgravación por la compra de viviendas.

\section{La ciudad global latinoamericana}

La ciudad del libre mercado está influenciada por las transformaciones del modelo de desarrollo que pasa de la sustitución de importaciones a otro basado en la desregulación y el mercado libre. Durante la sustitución de importaciones el desafío consistió en la creación de una nueva ciudad, de construir la vivienda y mejorar las condiciones laborales; este contexto social y económico afectó los intereses de los sectores de bajos recursos. Bajo la desregulación del mercado cambian los patrones tradicionales de segregación social, ya que los mercados de terrenos fueron desregulados progresivamente; además se produce un cambio en el patrón migratorio campo-ciudad por una migración intrarregional (Portes y Roberts, 2008). 
En este cambio de modelo, las características de los espacios urbanos asumen rasgos distintivos; en primer lugar se transita de la centralización hacia la descentralización; la concentración del poder económico y político de las capitales durante la etapa de la sustitución de importaciones forma parte del proceso descentralizador. Con el cambio en el modelo económico y las políticas de ajuste neoliberal se produce la descentralización del Estado. Así, a partir de 1990 "los organismos financieros bilaterales sostienen que la descentralización del Estado permite reforzar la democracia de los mercados" (Roberts y Portes, 2008, p. 428), es aquí cuando el Estado delega la responsabilidad social al mercado, y a un proyecto de ciudadanía participativa que demandará más del Estado.

En segundo lugar, otra característica de las ciudades con el cambio de modelo es la segregación e integración espacial que resulta del crecimiento desordenado de las ciudades latinoamericanas, lo cual generó dificultades para las familias de medianos y altos ingresos e impidió la suburbanización, en algunos casos los terrenos pertenecían al Estado y fueron invadidos. El patrón de segregación residencial ubica los sectores de bajos ingresos cercanos a los sectores de altos ingresos (Roberts y Portes, 2008). Permanece la imagen de los barrios amurallados con la intención de no mezclarse, los muros y las rejas protegen las viviendas, lo cual conduce a una mayor fragmentación de las ciudades. Por tanto, coexisten los barrios de los sectores de ingresos altos y medios, de forma fragmentada, con los barrios informales u otros de bajos ingresos.

En tercer lugar, las ciudades latinoamericanas muestran un decrecimiento en el tamaño relativo de las ciudades principales. La tendencia se evidencia a partir de los indicadores de porcentaje de población urbana en ciudades primadas, índice de primacía urbana (relación entre el tamaño de la principal área metropolitana y la suma de las siguientes tres) y evolución en la tasa de crecimiento urbano y metropolitano. Si bien, la primacía urbana empezó a declinar en algunos países antes del modelo neoliberal, con este ocurre una reorganización del sistema urbano.

En los países donde el modelo no fue aplicado, o débilmente aplicado, los niveles de primacía permanecieron inalterados. Al contrario, en aquellos países donde el modelo generó nuevas inversiones concentradas o cerca de ciudades principales, crecieron los niveles de primacía y nuevas megaciudades comenzaron a surgir (Portes y Roberts, 2008, p. 29). 
El crecimiento de las megaciudades alrededor de las primeras ciudades primadas es el resultado de la suburbanización de la población urbana y el surgimiento de las ciudades satélites donde se localizan la inversión. Según Portes, Dore-Cabral y Landolt (1997) se presentaron cambios significativos en el descenso de primacía urbana en República Dominicana y Jamaica, cambios poco significativos en Guatemala y la expansión de una nueva megalópolis en la Gran Área metropolitana de Costa Rica, que abastece las actividades exportadoras. Este planteamiento coincide con De Mattos (2010) quien lo denomina metropolización expandida con un crecimiento fuera del perímetro urbano, que da lugar a la formación de la región metropolitana articulada técnica y funcionalmente, como ocurre en las grandes metrópolis latinoamericanas y otras de menor tamaño como Costa Rica y Panamá.

La expansión urbana, en la mayoría de los países latinoamericanos, ocurre sin políticas de ordenamiento territorial y los cambios en las políticas macroeconómicas impactan la polarización social y su expresión espacial, es decir, el crecimiento urbano se expande hacia lugares sin acceso a servicios básicos e infraestructura y equipamiento urbano, en el caso de Buenos Aires “...este proceso originó una apropiación diferencial del espacio urbano: las clases medias y altas residiendo en las mejores localizaciones ecológicas y la clase trabajadora en áreas problemáticas desde el punto de vista ecológico" (Cerrutti y Grimson, 2008, p. 84).

En cuarto lugar, la evolución del mercado laboral muestra una tendencia al desempleo. Según el Consenso de Washington, se esperaba que el estímulo en la inversión de capital disminuyera el desempleo y subempleo; aunque ocurre todo lo contrario, las tasas de desempleo abierto y empleo informal se mantienen o han decrecido. El mercado laboral resultó afectado por la disminución del empleo industrial, especialmente en Argentina y en menor grado en Uruguay. En el caso de Chile el desempleo disminuyó y luego aumentó. En general disminuyó el empleo informal; no obstante, la seguridad social descendió dado el crecimiento precario de medianas y grandes empresas que carecen de seguridad social (Portes y Roberts, 2008).

En el caso chileno la transición hacia el mercado y el capital privado articula la oferta de oportunidades de integración social con dos consecuencias visibles. 
Por una parte, el mercado promueve la competencia, la creatividad y las oportunidades de negocio que estimulan la diferenciación en la estructura productiva y por otra alienta expectativas de integración social alrededor de intereses individuales y de acuerdo a la condición socioeconómica de cada cual (Sabatini y Wormald, 2008, p. 185).

La lógica individual impuesta incrementa las oportunidades de integración para aquellas personas que provienen de hogares con capital social y cultural y además pueden acceder a las mejores oportunidades educativas

En quinto lugar, persiste un desmejoramiento en las condiciones de pobreza y desigualdad. El deterioro en las condiciones del mercado laboral no afectó de igual forma a la población de los países mencionados; mientras en la década de los noventa en Argentina la pobreza se incrementó, en Chile disminuyó. En el caso argentino la consecuencia inmediata fue aumento de la desigualdad social dado la carencia de políticas sociales que incorporen a un gran sector de la sociedad al crecimiento económico, tal desigualdad genera condiciones de exclusión de oportunidades para la movilidad social. La tendencia en los países analizados se basó en la

[...] la persistencia de los niveles de desigualdad impulsada por la apropiación por parte de las clases dominantes de la mayor parte de los ingresos generados por el nuevo modelo y el estancamiento o por lo menos bajo ingreso de la tajada correspondiente a las clases trabajadoras (Portes y Roberts, 2008, p. 53).

Así lo muestran Portes y Hoffman (2003) en el análisis de la evolución de las clases en América Latina donde las tres clases dominantes (empleadores, ejecutivos/gerentes, profesionales universitarios) de ocho países (Brasil, Chile, Colombia, Costa Rica, El Salvador, México, Panamá y Venezuela) formaban apenas una décima parte de la PEA, con ingresos 14 veces superiores a la línea de pobreza.

En sexto lugar, se muestra un incremento del crimen y victimización. El menoscabo de las condiciones laborales y, en especial la creciente desigualdad, es la contrapartida a un incremento en la delincuencia y el robo. El consumismo de la sociedad global, la apertura económica y el deterioro en las condiciones de empleo para las clases de menor ingreso explica la búsqueda de otras formas opciones para obtener ingresos (Portes y Roberts, 2008). En las ciudades analizadas hubo un incrementó en la violencia y el delito, así como la sensación de inseguridad. 
La polarización social producto de la desigualdad social en América Latina refleja una nueva redistribución espacial, donde un mayor número de ciudadanos procuran una organización privada y eficiente en sus barrios que les proporcione de los servicios que antes eran públicos (Janoschka, 2002). Ante el debilitamiento del Estado en la gestión urbana, la seguridad se convirtió en una mercancía altamente rentable.

\section{De la ciudad polarizada a la ciudad fragmentada}

Las características de las ciudades latinoamericanas antes descritas coinciden con los planteamientos de Borsdorf (2003), el autor propone un modelo evolutivo de la ciudad latinoamericana. Así, la ciudad polarizada emerge en el modelo de sustitución de importaciones, entre 1920 y 1970, donde la rápida industrialización, en especial cerca de las principales vías de comunicación, estimula el crecimiento urbanístico con la proliferación de barrios populares y la vivienda social. En esta época aparecen los primeros centros comerciales, a forma de réplicas de los shopping centers norteamericanos y ejercen atracción hacia los barrios de lujo. La ciudad polarizada es el resultado de los principios de estructuración espacial y de subordinación, lo que explica un crecimiento hacia la periferia de las ciudades alimentada por el desarrollo urbano en el contexto de la industrialización, el poder estatal y la migración hacia la cuidad.

La ciudad fragmentada (1970 a la actualidad) está supeditada a la construcción de nuevas autopistas intraurbanas donde las zonas periurbanas se vuelven atractivas para las clases medias y altas. Tales autopistas acentuaron las estructuras lineales y conformaron los cimientos para la formación de estructuras de nodos fragmentados. Respecto a la estructuración espacial, los barrios marginales y viviendas sociales solo se observan en las ciudades caracterizadas por un alto porcentaje de pobreza extrema.

El autor establece un principio de fragmentación "una nueva forma de separación de funciones y elementos socio-espaciales, ya no -como antes- en una dimensión grande (ciudad rica-ciudad pobre, zona 
habitacional -zona industrial), sino en una dimensión pequeña” (Borsdorf, 2003, p. 44). Como ya se mencionó con anterioridad las barreras y los muros separan los diversos grupos sociales.

La ciudad fragmentada está conformada por dos elementos centrales 1) barrios cerrados "son urbanizaciones con dos o más departamentos o casas que cuentan con una infraestructura común y se encuentran cercados por muros o verjas, separados del espacio público mediante una barrera o puerta y vigilados por guardias o cámaras de video" (Borsdorf, 2003, p. 44). El otro elemento consiste en la localización de 2) elementos funcionales en el espacio urbano los malls, shopping centers, los urban entertainment centers y los business parks. En el caso de los malls no siempre ocurre una sustitución eficaz del espacio público o de la centralidad urbana, aunque las personas en sus prácticas socio espaciales reapropian estos espacios; mas bien sucede que la centralización del capital inmobiliario, financiero y comercial local favorece el establecimiento cercano a los sectores residenciales (Hidalgo, Santana, de Simone, y Arenas 2016).

En este contexto, la localización del consumo dentro del centro urbano pierde importancia, al igual que el comercio minorista; los centros de negocios empiezan a ubicarse en el perímetro urbano. Ambos elementos funcionales, los centros de consumo y los de negocios están dispersos por toda la periferia urbana, cerca de las principales vías de acceso y los aeropuertos. En fin, el crecimiento urbano responde a la demanda y consumo del espacio.

\section{La ciudad fragmentada: hacia una espacialidad del consumo}

Las transformaciones en la ciudad fragmentada crean tensión entre la cultura y la ideología. En esta dirección, el consumo es ideológico cuando estructura relaciones sociales sin tensiones, disimula la dominación y es presentada como un fenómeno de carácter universal. En este sentido, las necesidades de consumo son producidas socialmente entre las personas y las estrategias para la realización del consumo dependen de la inserción de clase. 
El consumo en la perspectiva de la "Nueva Geografía Cultural" profundiza en la sociedad urbana actual, las prácticas socio espaciales, la cultura de consumo y las formas en que los lugares son apropiados (Zapata, 2011). El consumo, como fenómeno, asume centralidad en la vida cotidiana y "ha hecho mancuerna con el miedo para formar parte esencial de los códigos con los cuales la sociedad construye sus imaginarios, delinea sus deseos, moldea sus prácticas cotidianas y construye espacios, que hemos de interpretar a partir de las claves de la simulación” (López, 2008, p. 122). La amalgama del imaginario del miedo y el imaginario del consumo legitiman la fragmentación, la desarticulación de los lugares en coherencia con los intereses del capital.

Para reflexionar acerca del consumo es clave conceptualizar ¿Qué es el consumo? De acuerdo con García (1995) "el consumo es el conjunto de procesos socioculturales en que se realizan la apropiación y usos de los productos" (p.42). Esta conceptualización coincide con Tondato (2010) al indicar que el consumo trasciende la adquisición de las mercancías hacia las prácticas y comportamientos en la satisfacción de las necesidades. Posee un alto valor simbólico por lo cual se incorpora en la vida cotidiana de la sociedad contemporánea. De igual forma, abarca múltiples contextos espaciales y temporales y se manifiesta en la conformación de las relaciones sociales en todas sus esferas y escalas.

La espacialidad del consumo integra elementos económicos y culturales que abren nuevos caminos dentro de las geografías culturales y económicas (Mansvelt, 2012). De un lado, la distribución desigual de la riqueza y los factores de producción, así como el acceso a las mercancías y los servicios asociados definen espacios de consumo que varían de acuerdo al estrato socioeconómico (Zapata, 2011).

En la perspectiva del consumo, desde las geografías económicas, aporta al establecer una justificación para el consumo, a la vez que reconoce el papel de la producción cultural como parte de la producción de valor económico; aunque contribuye poco en el significado de la práctica relacionada con el consumo para los grupos e individuos en contextos particulares (Gregson, 1995). A pesar del reconocimiento de que las geografías económicas están culturalmente constituidas y que las culturas están sujetas y construidas a través de los procesos económicos, la decisión del cómo establecer vínculos por medio de la investigación del consumo sigue siendo un desafío (Mansvelt, 2012). 
De otro lado, el consumo conjuga contrastes entre lo espectacular y lo seductor, los espacios ordinarios y los mundanos, a la vez que crea homogeneidad y heterogeneidad, integra lo local y lo global, el espacio y el lugar, la cultura y la economía (Goodman, Goodman, y Redclift, 2010). En consecuencia, a medida que las geografías de consumo se han desarrollado, tanto las limitaciones de los enfoques económicos como de los culturales han disminuido, con una creciente integración y aplicación de ideas de ambos campos de conocimiento (Mansvelt, 2012).

El consumos desde el enfoque cultural (García, 1995) abarca tres perspectivas o racionalidades. La racionalidad económica alude al proceso de expansión capitalista donde los productos son generados y la fuerza de trabajo es reproducida, en esta dirección el consumo no está dado por los gustos o necesidades, sino por las estructuras administradoras del capital. En la perspectiva sociológica y antropológica el consumo también presenta una racionalidad sociopolitica interactiva relacionada con la distinción entre grupos producida por el consumo, la innovación tecnológica y la moda. La tercera perspectiva alude a los aspectos simbólicos y estéticos de la racionalidad consumidora, de acuerdo a la diferenciación de clases y de grupos sociales y el valor simbólico de los objetos.

En el campo de la Geografía cultural, Kneale y Dwyer (2008) también analizan el consumo desde tres perspectivas. La primera, de índole económica, cuestiona al consumo como uso o necesidad de las mercancías; tal cuestionamiento trasciende la distinción entre el valor de uso y el valor de cambio, de acuerdo con Baudrillard (2012) los objetos poseen un valor social y simbólico de los signos "lo que hay es producción social de un material de diferencias, de un código de significaciones y de valores de estatus, sobre el cual se sitúan los bienes, los objetos y las prácticas de consumo” (p. XXX). Por su parte, para David Harvey (1998), la transición de la producción fordista a la acumulación flexible del capital está marcada por la innovación tecnológica, el régimen de acumulación y los modos regulatorios que inciden en la creación simbólica de las necesidades por el consumo.

La segunda perspectiva relacionada a la creación y visualización de identidades asume el consumo como actividad que contribuye en la creación de identidades y relaciones sociales hasta el punto de otorgar valores humanos a las mercancías. De esta forma, el valor de uso de las mercancías se puede convertir 
en un fetiche, un término en su origen aplicado a objetos rituales, está referido a la atribución de valores humanos a objetos no humanos. En este sentido, los objetos pueden ser descritos como deportivos, informales o sexi, aunque no sea ninguno de estos; simplemente se les atribuyen valores humanos. Su valor de uso está en función de la calidez, la comodidad, u otros aspectos de la utilidad, mientras que sus valores de intercambio o fetiche son adquiridos a través del diseño, el marketing y la publicidad. Esta concepción del consumo sugiere el rol de las TIC en la creación de identidades (Kneale y Dwyer, 2008). De acuerdo con García (1995) el acto del consumo forma parte de la construcción de las identidades ya que la selección de los bienes implica una apropiación de aquello considerado públicamente valioso con relación a la forma de integrarse y distinguirse en la sociedad.

La tercera vertiente del consumo apunta a las culturas materiales y surge como crítica a la visión materialista del uso de los objetos propuestas por Douglas e Isherwood (1996) quienes sugieren que las mercancías además de ser buenas para comer, vestirse y cobijarse son útiles como medio no verbal en la transmisión de la cultura. De hecho, el consumo juega un papel importante en las relaciones sociales y los espacios sociales; y más allá de suponer el significado de los objetos, su valor simbólico o la forma de construir identidad trasciende hacia la naturaleza social del consumo como la materialidad de las prácticas y procesos de consumo. Esta perspectiva más contextual en el enfoque al consumo que se ha vuelto cada vez más influyente dentro de la geografía (Kneale y Dwyer, 2008). Y debería ser estudiada como parte integral constitutiva de las relaciones sociales. El aporte de esta perspectiva radica en el énfasis hacia las prácticas materiales encarnadas y performativas, así como la cultura material y de las cosas (Mansvelt, 2012).

\section{CONSIDERACIONES FINALES}

La reconfiguración del sistema capitalista en América Latina se interpreta a partir de las transformaciones espacio temporales, las cuales conducen a un desarrollo geográfico desigual evidenciado en la reestructuración de las ciudades. Es aquí donde la globalización reorganiza geográficamente los espacios del capital al inducir una profunda fragmentación de los espacios. De forma simultánea, las ciudades forman un tejido de interconecciones globales, y a su vez permanecen 
fragmentadas. Los sectores globales de la economía están dirigidos a los ganadores de la globalización, o sea, los grupos de mayor ingreso; en tanto los perdedores de la globalización conforman un sector de exclusión social.

Si bien desde sus orígenes, la ciudad colonial segregó y estableció una división étnica y racial donde la clase dominante se estableció en el centro de la ciudad, mientras que los otros grupos se ubicaron en las zonas agrícolas más alejadas de la ciudad. En la ciudad actual, el centro tradicional se ha ido despoblando, en algunos casos gentrificado, y las clases dominantes se han trasladado a las áreas periurbanas. De esta forma, el centro de las ciudades se convierte en un espacio de intercambio comercial de bienes y servicios que coexiste con los espacios construidos por el capital global: los malls, shopping centers, los urban entertainment centers y los business parks.

La transición de un modelo agroexportador hacia una economía basada en la sustitución de importaciones implicó una fuerte transformación de la morfología urbana, apenas un preámbulo a la economía del libre mercado. En el caso de Costa Rica supuso la conversión de usos agrícolas a usos urbanos sin políticas claras de ordenamiento territorial, vinculado a la dinámica especulativa de desregulación del mercado inmobiliario. Estas dinámicas forman parte de las reformas neoliberales que influyen en el proceso de fragmentación de las ciudades.

La terciarización de las economías urbanas está articulada a partir del consumo y su dimensión cultural, aquí adquiere sentido el simbolismo del consumo en una economía de mercado hasta crear la segregación de unos grupos respecto a otros, de acuerdo a los objetos consumidos y donde las Tecnologías de la Información y Comunicación promueven los imaginarios del consumo.

\section{REFERENCIAS}

\footnotetext{
Albino, S. y. Barsky, A. (1997). El tercer espacio. Ampliando el horizonte de la imaginación geográfica (Edward Soja) Geographikós, 8 (Segundo Semestre), 71-76.

Augé, M. (2008). Los no lugares: espacios del anonimato. Barcelona: Gedisa.

Baudrillard, J. (2009). La sociedad de consumo: sus mitos, sus estructuras. Madrid: Siglo XXI España Editores, S.A.

Berger, J. (1987). Loving a Cold Climate. The Guardian, 4(12).
} 
Bhabha, H. K. (2002). El lugar de la cultura. Buenos Aires, Argentina: Ediciones Manantial.

Borsdorf, A. (2003). Cómo modelar el desarrollo y la dinámica de la ciudad latinoamericana. EURE (Santiago), 29(86), 37 49. Recuperado de https://www.redalyc.org/html/196/19608602/

Brenner, N. (2009). A Thousand Leaves:Notes on the Geographies of Uneven Spatial Development. Recuperado de https://www.researchgate.net/publication/265495657_A_Thousand_Leaves_Notes_on_the_Geographies_of_Uneven_Spati al_Development

Cerrutti, M. y Grimson, A. (2008). Buenos Aires, neoliberalismo y después. Cambios socioeconómicos y respuestas populares. En Portes, A, Roberts, B. y Grimson, A. (Eds.), Ciudades latinoamericanas: un análisis comparativo en el umbral del nuevo siglo. México: Prometeo libros.

De Mattos, C. A. (2010). Globalización y metamorfosis metropolitana en América Latina: de la ciudad a lo urbano generalizado. Revista de Geografía Norte Grande, (47), 81-104. Recuperado de https://scielo.conicyt.cl/scielo.php?pid=S0718-34022010000300005\&script=sci_arttext\&tlng=en

De Sousa Santos, B. (2000). Crítica de la razón indolente, contra el desperdicio de la experiencia. Recuperado de http://biblioteca.clacso.edu.ar/Argentina/iigg-uba/20161110024742/Critica.pdf

Douglas, M., \& Isherwood, B. (1979). The World of Goods: towards an anthropology of consumption. New York.

Foucault, M., y Miskowiec, J. (1986). Of other spaces. Diacritics, 16(1), 22-27.

García, N. C. (1995). Consumidores y ciudadanos: conflictos multiculturales de la globalización: Grijalbo.

Goodman, M. K., Goodman, D., y Redclift, M. (2010). Introduction: Situating consumption, space Consuming Space: placing consumption in perspective Farnham, England and Burlington VT: Ashgate.

Gregson, N. (1995). And now it's all consumption? Progress in Human Geography, 19(1), 135-141. Recuperado de https://www.researchgate.net/profile/Nicky_Gregson/publication/240738816_And_Now_It\%27s_all_Consumption/links/5 803f72308ae23fd1b68a1e2/And-Now-Its-all-Consumption.pdf

Grimson, A. (2008). Prefacio. En, A. Portes., B. Roberts y A. Grimson (eds.), Ciudades latinoamericanas: un análisis comparativo en el umbral del nuevo siglo. México: Prometeo libros.

Harvey, D. (1998). La condición de la posmodernidad: Buenos Aires: Amorrortu.

Harvey, D. (2004). Spaces of Neoliberalization: Towards a Theory of Uneven Geographical Development. Alemania: Franz Steiner Verlag. Recuperado de https://goo.gl/TbJwRq

Harvey, D. (2014). Diecisiete contradicciones y el fin del capitalismo: IAEN-Instituto de Altos Estudios Nacionales del Ecuador.

Hiernaux, D., y Lindón, A. (2004). Desterritorialización y reterritorialización metropolitana: la ciudad de México. Doc. Anàl. Geogr, 44, 71-88. Recuperado de http://www.raco.cat/index.php/DocumentsAnalisi/article/download/31833/180044

Hidalgo, R., Volker, P., y Ramírez, N. (2014). La ciudad inmobiliaria: mecanismos institucionales, relaciones de poder y mercantilización del medio natural. El caso del Área Metropolitana de Valparaíso. Scripta Nova. Revista electrónica de geografía y ciencias sociales, 18.

Hidalgo, R., Santana, D., de Simone, L., y Arenas, F. (2016). Geografías del comercio en Santiago de Chile (1990-2010): de la reestructuración comercial al policentrismo inmobiliario. Revista Geográfica Venezolana, 57(1), pp. 14-37.

Janoschka, M. (2002). El nuevo modelo de la ciudad latinoamericana: fragmentación y privatización. EURE, 28(85), 11-29. Recuperado de http://www.scielo.cl/scielo.php?script=sci_arttext\&pid=S0250-71612002008500002

Janoschka, M. (2011). Geografías urbanas en la era del neoliberalismo. Una conceptualización de la resistencia local a través de la participación y la ciudadanía urbana. Investigaciones geográficas, 76, 118-132. Recuperado de http://www.scielo.org.mx/scielo.php?script=sci_arttext\&pid=S0188-46112011000300009

Janoschka, M. (2012). Imaginarios del turismo residencial en Costa Rica. Negociaciones de pertenencia y apropiación simbólica de espacios y lugares: una relación conflictiva. Recuperado de http://www.michael-janoschka.de/download/665/ 
Kneale, J., y Dwyer, C. (2008). Consumption. En Duncan, J, Johnson y Schein, R. (Eds.), A companion to cultural geography (pp. 298-315).

Lefebvre, H., y Nicholson-Smith, D. (1991). The production of space. Estados Unidos: Blackwell Oxford. Recuperado de http://www.mom.arq.ufmg.br/mom/arq_interface/1a_aula/the_production_of_space.pdf

Lévy, J. (2006). Geografía y mundialización. Lindón, A y Hiernaux (comp) En Tratado de geografía humana (pp. 273-302). Anthropos.

López, L. L. (2008). Tijuana: imaginarios globales, fortificaciones locales. Sociológica (México), 23(66), 121-153.

Recuperado de http://www.scielo.org.mx/scielo.php?pid=S0187-01732008000100006\&script=sci_arttext

Löw, M. (2013). O spatial turn: para uma sociologia do espaço. Tempo Social, revista de sociologia da USP, $25(2), 18$.

Recuperado de http://www.scielo.br/scielo.php?pid=S0103-20702013000200002\&script=sci_arttext\&tlng $=$ pt

Mansvelt, J. (2008). Geographies of consumption: citizenship, space and practice. Progress in Human Geography, 32(1), 105-117.

Mansvelt, J. (2010). Geographies of consumption: engaging with absent presences. Progress in Human Geography, 34(2), 224-233. Recuperado de https://www.researchgate.net/profile/Juliana_Mansvelt/publication/249872518_Geographies_of_consumption_Engaging_ with_absent_presences/links/574e986808ae82d2c6be31a5/Geographies-of-consumption-Engaging-with-absentpresences.pdf

Mansvelt, J. (2012). Consumption geographies: turns or intersections? Encounters and Engagements between Economic and Cultural Geography (pp. 47-64): Springer

Mary, D., y Baron, I. (1996). The World of Goods: Towards anthropology of consumption. New York.

Portes, A. (1997). Neoliberalism and the sociology of development: emerging trends and unanticipated facts. Population and development review, 229-259.

Portes, A., Dore-Cabral, C., y Landolt. (1997). The Urban Caribbean: Transition to the New Global Economy. Baltimore, Estados Unidos: Johns Hopkins University Press.

Portes, A., y Roberts, B. (2008). Introducción. La ciudad bajo el libre mercado. In A. Portes, Roberts, A y Grimson, A. (Eds.), (Ed.), Ciudades latinoamericanas: un análisis comparativo en el umbral del nuevo siglo. México: Prometeo libros.

Portes, A., y Hoffman, K. (2003). Las estructuras de clase en América Latina: composición y cambios durante la época neoliberal. Santiago, Chile: ONU. Recuperado de http://archivo.cepal.org/pdfs/2003/S2003708.pdf

Roberts, B. y Portes, A. (2008). Conclusión. Enfrentando la ciudad del libre mercado. La acción colectiva urbana en América Latina, 1980-2000. En. Portes, A; Roberts, B y Grimson, A. (Ed.), Ciudades latinoamericanas: un análisis comparativo en el umbral del nuevo siglo. México: Prometeo libros.

Romero, Alberto y Mary Vera Colina, Analí. Las Empresas Transnacionales y Los Países En Desarrollo. En Revista de la Facultad de Ciencias Económicas y Administrativas. (Colombia) Vol. XV. No. 2, (Julio-Diciembre, 2014), pp. 58-89.

Sabatini, F., y Wormald. G. (2008). Santiago de Chile bajo la nueva economía (1980-2000). Crecimiento, modernización y oportunidades de integración social. In A. Portes, Roberts, A y Grimson, A. (Eds.), (Ed.), Ciudades latinoamericanas: un análisis comparativo en el umbral del nuevo siglo. México: Prometeo libros.

Santos, M. (2004). Por otra globalización: del pensamiento único a la conciencia universal. Convenio Andrés Bello: Bogotá.

Santos, M. (2000). La naturaleza del espacio: técnica y tiempo, razón y emoción (No. 711). Ariel: Barcelona.

Soja, E. W. (1989). Postmodern geographies: The reassertion of space in critical social theory. London: Verso.

Tondato, M. P. (2010). Uma perspectiva teórica sobre consumo e cidadania na contemporaneidade. Conexiones-Revista Iberoamericana de Comunicación, 2(2), 5-18. Recuperado de https://www.researchgate.net/profile/Marcia_Tondato/publication/260991781_Uma_perspectiva_teorica_sobre_consumo_ e_cidadania_na_contemporanei/links/0f317532fa2d63c05b000000.pdf 
Vargas, L. S. (2012). Crisis económica mundial: Elementos para una crítica de los paradigmas teóricos e ideológicos que sustentan la propuesta neoliberal. Revista Rupturas, 2(1), 142-169. Recuperado de

http://investiga.uned.ac.cr/revistas/index.php/rupturas/article/view/176

Zapata, J. Z. (2011). Geografía cultural y consumo. Revista de relaciones internacionales, estrategia y seguridad, 6(2), 163-

175. Recuperado de http://www.scielo.org.co/pdf/ries/v6n2/v6n2a08.pdf 